\title{
MARKETING SOCIETAL: UMA CONTRIBUIÇÃO PARA O CRESCIMENTO SUSTENTÁVEL DAS ORGANIZAÇÕES
}

\author{
SOCIETY MARKETING: A CONTRIBUTION FORTHE \\ PROGRESS SUSTAINABLE OF THE ORGANIZATIONS
}

Recebido - 27.05.10

Aceito - 12.03.2011

\begin{abstract}
Edson Coutinho Silva ${ }^{1}$, Silvio Augusto Minciotti ${ }^{2}$ e Maria do Carmo Romeiro ${ }^{3}$
\end{abstract}

\begin{abstract}
Resumo
Hoje é indiscutível a necessidade de as organizações incorporarem o desenvolvimento sustentável ou, pelo menos, minimizarem os impactos causados no desenvolvimento de seu processo produtivo. É vital, para as organizações, a realização de ações que evidenciem a sua parcela de contribuição para com o meio social. Diante disso, as estratégias de marketing nas organizações vêm procurando desenvolver ações voltadas à satisfação de seus clientes, despertando novos desejos nas necessidades já existentes e atendendo-os com o maior nível de qualidade possível em todos os processos. Entretanto, isto não tem sido o suficiente, pois os consumidores têm exigido mais: querem organizações comprometidas com o bem-estar social da sociedade. Com a acirrada concorrência no mercado, as organizações buscam diferenciais essenciais que garantam a sua vantagem competitiva sobre as demais organizações. Tendo em vista tal cenário, a administração conta com uma ferramenta que traz benefícios a todos os envolvidos no processo, que é o Marketing Societal, em que a organização investe no social, provisionando um retorno de resultados para a organização.
\end{abstract}

Palavras-chave: Marketing. Marketing Societal. Desenvolvimento Sustentável.

1 Professor Universitário do Centro Universitário da Fei e Trevisan Escola de Negócios. Mestre em Administração e Doutorando em Ciências Sociais pela Pontifícia Universidade Católica de São Paulo (PUC-SP). Brasil. E-mail: coutinho_ed@yahoo.com.br

2 Mestre e Doutor em Administração pela Faculdade de Economia, Administração e Contabilidade da Universidade de São Paulo (FEA-USP). Professor do Mestrado em Administração pela Universidade Municipal de São Caetano do Sul (USCS). Atualmente, é reitor da mesma instituição. Brasil. E-mail: silviominciotti@uol.com.br

3 Mestre e Doutora em Administração pela Faculdade de Economia, Administração e Contabilidade da Universidade de São Paulo (FEA-USP). Professora e Coordenadora de Pesquisa pela Universidade Municipal de São Caetano do Sul (USCS). Brasil. E-mail: mromeiro@uscs.edu.br 


\begin{abstract}
Today the necessity of the organizations in to add the sustainable development, or at least to reduce the impacts caused in the development of its productive process unquestionable. The action accomplishment is vital for the organizations that its parcel of contribution evidences for with the social environment. The strategies of Marketing in the organizations looking for to develop actions directed to the satisfaction of its customers, creating new desires in the existing necessities already and taking care of them with the biggest level of possible quality in all the processes. However, this has not been the sufficient, the customers have demanded more, they want organizations compromised to the social welfare of the society. With the incited competition in the market, the organizations search differentials essential that they guarantee its competitive advantage on the too much organizations. The administration has on tool that brings benefits to all the involved ones in the process, which is the Society Marketing, where the organization invests in the social, looking for a return of overcomes for the organization.
\end{abstract}

Keywords: Marketing. Society Marketing. Sustainable Development.

\title{
1 INTRODUÇÃO
}

Desde a última década tem sido visível e muito comentado o fato de as empresas brasileiras estarem voltando a atenção para o Marketing na Sustentabilidade, seja por meio de campanhas para dar visibilidade às ações de responsabilidade ambiental, seja por meio de ações institucionais. Isso mostra a tendência global das empresas que tratam o assunto Sustentabilidade não mais como um slogan comercial, mas sim como um item de destaque na estratégia de negócio e na cartilha de seus princípios corporativos. O aspecto mais relevante acerca desse assunto é que essa tendência, antes vista apenas em empresas B2C (Business to Consumer), agora também pode ser constatada em empresas B2B (Business to Business).

Em virtude de seu amplo conteúdo e da ausência de um escopo definido, o conceito de Sustentabilidade suscitou inúmeras críticas, podendo ser interpretado como um novo modelo de desenvolvimento ou apenas um redesenho do capitalismo dominante. No entanto, a conformação de um novo perfil sócio-técnico-econômico altera os condicionantes que demarcam a estrutura e as funções das organizações, razão pela qual o domínio econômico precisa reconhecer os principíos de Sustentabilidade enquanto se processam novas relações entre o marketing e a sociedade.

Consequentemente, a sustentabilidade se ergue a partir de três pilares independentes, mas interralacionados: o econômico, o social e o ambiental. Constata-se que esse modelo fortalece o sentido das organizações como socialmente responsáveis pela fragilidade do ambiente físico, pelo comprometimento de reavaliar os níveis de consumo e pela transformação do desenvolvimento da sociedade. Tendo em vista a sustentabilidade, a dimensão da prática de ações sociais e ambientais pelas organizações é um fenômeno que vem emergindo a cada dia com mais adeptos no meio empresarial, procurando compreender esta "nova" relação que está se estabelecendo entre os consumidores e as organizações (CAMARGO, 2003). Gradativamente o marketing evolui em sintonia com as mudanças nas relações de negócios e nas estruturas de produção, buscando projetar a imagem de uma organização sustentável - a partir da legitimidade de suas ações - na mente do consumidor. Cabe lembrar que as organizações da economia capitalista do pós-guerra atende a uma sociedade de consumo capitaneada pelas estratégias de marketing. 
Muitos membros de sociedade questionam as estratégias de marketing por estimular o excessivo consumo, colocando em risco o equilíbrio ambiental no planeta e contribuindo para o aumento da pobreza extrema e das distorções sociais (KOTLER; ROBERTO, 1992). Ao contrário, a proposta de Marketing Societal apoia-se na adoção de níveis superiores de responsabilidade, utilização de recursos naturais e na busca de solução para problemas existentes. O Marketing Societal é um instrumento que surge para rebater padrões atuais de comportamento e de consumo, ressaltando que os comportamentos atuais precisam ser alterados com vistas a limitar a degradação ambiental.

Para profissionais de marketing, a questão ambiental deixa de ser um problema para tornar-se parte de uma solução, ou seja, a oportunidade de inserir, em seu negócio, um segmento de mercado emergente e ter um aumento da credibilidade da organização junto à sociedade, através da qualidade e competitividade de seus produtos, decorrente de uma nova percepção de valor: de Sustentabilidade. Por tudo isso, a premissa central deste ensaio é de que o mercado se desloca e muda com muito mais rapidez do que a capacidade de reação e resposta da sociedade. Os compradores buscam produtos que tenham "legitimidade de seu impacto" - que vão em consonância com questões valorizadas pela sociedade - tendo em vista a Sustentabilidade. O desafio do Marketing Societal é o de fortalecer as relações entre organizações e sociedade em prol de um desenvolvimento sustentável e, consequentemente, aproveitar oportunidades de crescimento dos resultados empresariais.

\section{ORGANIZAÇÃO SUSTENTÁVEL: EM BUSCA DE UM DIFEREN- CIAL COMPETITIVO}

Para o desenvolvimento sustentável de uma comunidade é indispensável uma mudança de curso ecológico, pois a mudança aceleraria o desenvolvimento do progresso técnico ecologicamente relevante. E a mudança global de curso ecológico deve partir dos países industrializados, por motivos racionais, da justiça e também por razões factíveis (SMITH, RIBAS, 2006). Para uma organização agir de maneira ecologicamente responsável, é necessário que as organizações desempenhem os seguintes papéis: (a) compatibilidade ambiental dos processos de produção dos produtos finais e dos produtos intermediários; (b) precauções de segurança no transporte e armazenamento de materiais ambientalmente problemáticos; (c) precauções para prevenção de acidentes durante a produção e o transporte; (d) grau de intensidade de matériasprimas e de energia da organização; (e) quantidade e composição do lixo; (f) esforços constantes para reaproveitamento de matéria-prima; e (g) favorecimento de tecnologia ecoeficientes (DONAIRE, 1995).

Na perspectiva dos administradores "verdes", a preocupação com o meio ambiente fez com que as pessoas agissem na compra de produtos considerados ambientalmente saudáveis. $\mathrm{O}$ consumerismo sustentável surgiu das preocupações na década de 1970, mas só se intensificaram no final da década de 1980, com os acidentes industriais, mudança climática, doença e outros. Estes fatores fizeram surgir uma "nova" era do marketing, do qual revela que os produtos passam a ser avaliados não apenas com base no desempenho ou preço, mas nas ações de sustentabilidade dos fabricantes (SCHENINI et al., 2000). Nesse contexto, apresentam-se algumas alternativas para as organizações desenvolverem programas proativos de sustentabilidade: (a) desenvolver e implementar uma política sustentável dentro da organização; (b) adiantar-se aos problemas, ou seja, manifestar-se publicamente aos interessados que a organização está agindo; e (c) comunicar ações divulgando a postura da organização (OTTMAN, 1994). 
Para Lages e Vargas Neto (2002), os consumidores consideram as ações de sustentabilidade da organização, levando em consideração as diferenças entre os produtos "verdes" e os "nãoverdes" na avaliação das escolhas. Deve-se observar esta oportunidade não somente como uma maneira de "fazer a coisa certa", mas também para aumentar a imagem e marca da organização no segmento-alvo, economizar recursos e abrir segmentos de mercado para consumidores que queiram alta qualidade de vida. De acordo com Motta e Rossi (2003), algumas organizações acreditam que o consumerismo sustentável é apenas um modismo, relutando em mudar suas operações e produtos. Para que uma organização seja "verde", é necessário: (a) assumir um compromisso; (b) desenvolver um plano; (c) fazer auditoria das operações; (d) nomerar gestores "verdes"; (e) envolver empregados; e (f) espalhar a notícia.

Com relação ao desenvolvimento de produtos "verdes", Ottman (1994) aponta três diretrizes que devem ser consideradas: (a) adotar uma estratégia completa para enverdeamento do produto e avaliar suas implicações ambientais; (b) maximizar o retorno potencial, concentrando-se em tecnologias bem definidas e aceitas; e (c) incorporar as necessidades e desejos referentes ao comportamento do consumidor, levando em consideração quatro fatores apontados por Kotler e Keller (2006): culturais, sociais, pessoais e psicológicos. Cabe ainda ressaltar que os mesmos devem atender aos padrões de qualidade sugeridos para produtos verdes, que é a incorporação da certificação FSC (Forest Stewardship Council) e da ISO 14000 - padrões de qualidade aderentes ao meio ambiente.

Quadro 1: Desenvolvimento de Produtos "Verdes"

\begin{tabular}{|c|c|}
\hline $\begin{array}{c}\text { Aquisição e processamento } \\
\text { de matérias-primas }\end{array}$ & $\begin{array}{l}\text { - Conservação de recursos naturais; } \\
\text { - Proteção de habitats naturais; } \\
\text { - Minimização do lixo e preservação contrária à poluição; } \\
\text { - Transporte; } \\
\text { - Uso de recursos renováveis; } \\
\text { - Uso de materiais reciclados. }\end{array}$ \\
\hline Produção e distribuição & $\begin{array}{l}\text { - Uso mínimo de recursos materiais - evitar desperdícios; } \\
\text { - Uso e liberação de tóxicos; } \\
\text { - Geração e manuseio de lixo; } \\
\text { - Eficiência energética; } \\
\text { - Uso de água; } \\
\text { - Emissões para o ar, terra e água. }\end{array}$ \\
\hline $\begin{array}{l}\text { Uso de produto } \\
\text { e embalagem }\end{array}$ & $\begin{array}{l}\text { - Eficiência energética; } \\
\text { - Conservação de recursos naturais; } \\
\text { - Saúde do consumidor e segurança ambiental. }\end{array}$ \\
\hline $\begin{array}{l}\text { Uso de posterior } \\
\text { e descartabilidade }\end{array}$ & $\begin{array}{l}\text { - Reciclabilidade e facilidade de reutilização, refabricação e reparo; } \\
\text { - Durabilidade; } \\
\text { - Biodegradabilidade; } \\
\text { - Seguro quando incinerado ou colocado em aterro sanitário. }\end{array}$ \\
\hline
\end{tabular}

Fonte: Adaptado de Ottman (1994, p. 103-105). 
Ottman (1994) afirma que as organizações que desenvolvem produtos "verdes" devem seguir um Inventário de Ciclo de Vida (ICV) que se refere a um processo que quantifica a energia, recursos e emissões para o meio ambiente, associadas a um produto durante todo o ciclo de vida, sendo responsável pelo impacto ambiental de procura de matérias-primas, fabricação e produção, embalagem, distribuição e características de uso, até a fase posterior ao uso e descarte do produto, como segue no quadro 1. Nesse sentido, o ICV é útil para: (a) comparar o uso de energia e recursos e as emissões ambientais associadas não só a produtos existentes, como também às suas alternativas; (b) identificar áreas significativas para aperfeiçoamento no uso de energia e redução de lixo; (c) avaliar o uso de energia e recurso e as emissões ambientais associadas a mudanças propostas em fabricação ou embalagem de produtos.

Outra questão relacionada à gestão de organizações sustentáveis que deve ser abordada é o papel da governança corporativa. Uma organização com boa governança corporativa é responsável e transparente para com seus acionistas e outras partes interessadas, tais como: empregados, credores, clientes e sociedade em geral. O aprimoramento da governança corporativa permite que a organização reconheça suas responsabilidades ambientais e sociais e saiba agir no sentido de cumpri-las. Assim sendo, a governança corporativa contribui para o crescimento sustentável em longo prazo (ANDRADE; ROSSETTI, 2006).

Com relação à imagem e à marca, outra preocupação dos profissionais de marketing de uma organização está relacionada ao branding. O termo branding significa dotar produtos e serviços com o poder de uma marca (KOTLER; ARMSTRONG, 2007). Está totalmente relacionado a criar diferenças. Questões referentes ao meio ambiente, produtos "verdes" e sustentabilidade têm sido bastante utilizadas pelos profissionais de marketing no momento de ensinar os consumidores "quem" é o produto, bem como a "que" ele se depara e "por que" o consumidor deve interessar-se por ele (MAIGNAN; FERREL, 2004).

Portanto, o branding diz respeito a criar estruturas mentais e a ajudar o consumidor a organizar seu conhecimento sobre os produtos e/ou serviços, de forma que torne sua tomada de decisão mais esclarecida e, nesse processo, gere valor à organização. Entretanto, para que as estratégias de branding sejam bem-sucedidas e o valor da marca seja criado, os consumidores devem ser convencidos de que existem diferenças significativas entre as marcas numa categoria de produto e/ou serviço (KOTLER; KELLER, 2006). No caso da sustentabilidade, fazer com que o consumidor perceba as diferenças existentes entre um produto "verde" e um "nãoverde". O segredo do branding é o fato de os consumidores não acharem que todas as marcas na categoria são iguais (STRAUGHAN; ROBERTS, 1999).

Para Ottman (1994) e Corrado (1994), uma última questão a ser abordada é a comunicação dos benefícios dos produtos, que é algo desafiador, porque os benefícios, às vezes, não são tangíveis. Nesse contexto, as estratégias para projetar a salubridade dos produtos são: (a) reconhecer o poder das pessoas; (b) tornar o assunto pessoal; (c) reconhecer as diferenças existentes nos compromissos sustentáveis dos consumidores; (d) ser otimista e positivo; (e) educar; (f) tranquilizar sobre o desempenho; (g) estabelecer credibilidade para evitar recuo; (h) ser um líder; (i) comunicar produtos "verdes" como parte de uma política corporativa de excelência sustentável; (j) ser claro e proeminente; (k) não exagerar; (l) fornecer informações completas; (m) manter mensagens consistentes; e (n) considerar o impacto sustentável nas estratégias de marketing.

Segundo Schenini et al. (2006), o desenho da sustentabilidade salienta um novo processo de produção e de gestão, sob a égide econômica, social e ambiental, exigindo não apenas limites para os movimentos de marketing, mas uma agenda que incorpore o sentido e o objetivo à produção econômica, substituindo o "monólogo" pelo "diálogo" com a sociedade, como 
forma de identificar os efeitos de suas ações junto aos grupos de interesse. Mediante isso, o marketing se atrela ao despertar da consciência que cerca o desenvolvimento sustentável, uma vez que a incorporação desses valores ao sistema de produção assegura resultados eficientes na proteção do meio ambiente. Na perspectiva de Baker (1995), ao promover os valores de sustentabilidade, o desenvolvimento de novos produtos com atributos sociais e ambientais assegura o melhor desempenho, pelas vantagens diferenciadas. Portanto, as organizações devem avaliar os níveis de consumo das populações e as implicações dos seus estilos de vida em torno dos recursos hídricos, qualidade do ar, clima, florestas, diversidade biológica e saúde humana.

\section{MARKETING SOCIETAL: O BEM-ESTAR DA SOCIEDADE SO- BREPÕE O CONSUMO INDIVIDUAL}

Ironicamente, uma das mais antigas definições de marketing seja, talvez, a mais expressiva do conceito societal de marketing. Em 1947, Paulo Mazur (apud SCHEWE, SMITH, 1982, p. 13) sustenta que "Marketing é a entrega de um padrão de vida à sociedade", representando a qualidade de vida.

Até a década de 1960, o conceito do Marketing enfatizava, "dar ao cliente o que ele deseja" sem fazer julgamentos de seus desejos sob a ótica da sociedade. Isso incluía supri-lo com cigarros, automóveis de elevado consumo de combustível, garrafas sem retorno, detergentes, alimentos saborosos, mas não nutritivos e qualquer coisa que the fosse conveniente e satisfizesse. As organizações preocupavam-se com a satisfação dos consumidores em curto prazo, mas não com seu bem-estar em longo prazo. A partir do final da década de 1960, alguns consumidores começaram a questionar sobre a obrigação que as organizações teriam de alertar sobre efeitos nocivos e os perigos dos produtos. Foi assim que se iniciou uma importante revisão conceitual de marketing no meio acadêmico, levando Kotler (1978, p. 62) a afirmar que Marketing Societal "é uma orientação para as necessidades dos consumidores, apoiados pelo Marketing integrado", com o objetivo de "gerar a satisfação dos consumidores e o bem-estar dos consumidores em longo prazo, como o meio para se atingir os objetivos organizacionais".

Ao acrescentar o bem-estar dos consumidores em longo prazo, eleva-se o conceito de servir bem ao mercado e a sociedade de uma organização, considerando: a) a criação de clientes satisfeitos e a contribuição para a qualidade de vida; b) produtos combinando elevado atrativo e alto benefício aos consumidores; e c) os consumidores irão adquirir produtos de organizações preocupadas com a satisfação e o bem-estar em longo prazo (SILVA, MINCIOTTI, 2004).

Segundo Richers (2000), o que se pode observar é que as transformações conceituais do marketing surgiram muito influenciadas pelos movimentos consumeristas mundiais, de um lado e, do outro lado, do reconhecimento de que o conceito de marketing poderia ser aplicado tanto a organizações privadas como às organizações que não necessariamente visassem o lucro nas suas transações, tais como igrejas e hospitais, entre outros, ampliando, assim, seus horizontes para funções sociais e outras para o bem-estar da comunidade.

Kotler e Armstrong (2007) esclarecem que no Marketing Tradicional - ou Comercial - a relação mutuamente favorável entre consumidor-organização pode não o ser para a sociedade como um todo. Neste ponto entra o Marketing Societal, questionando se o Marketing Tradicional - ou Comercial - é adequado a uma época com problemas ambientais, escassez de recursos naturais, rápido crescimento populacional, problemas econômicos no mundo inteiro e serviços sociais negligentes. De acordo com Giacomini (1993), os valores humanitários ou societais es- 
tão acima dos interesses individuais ou corporativos; o Marketing Societal, ao contrário do comercial, não busca soluções para problemas mercadológicos; mas evitar que a organização tenha problemas vitais quando da prática de uma estratégia que implique agressão a um valor societal.

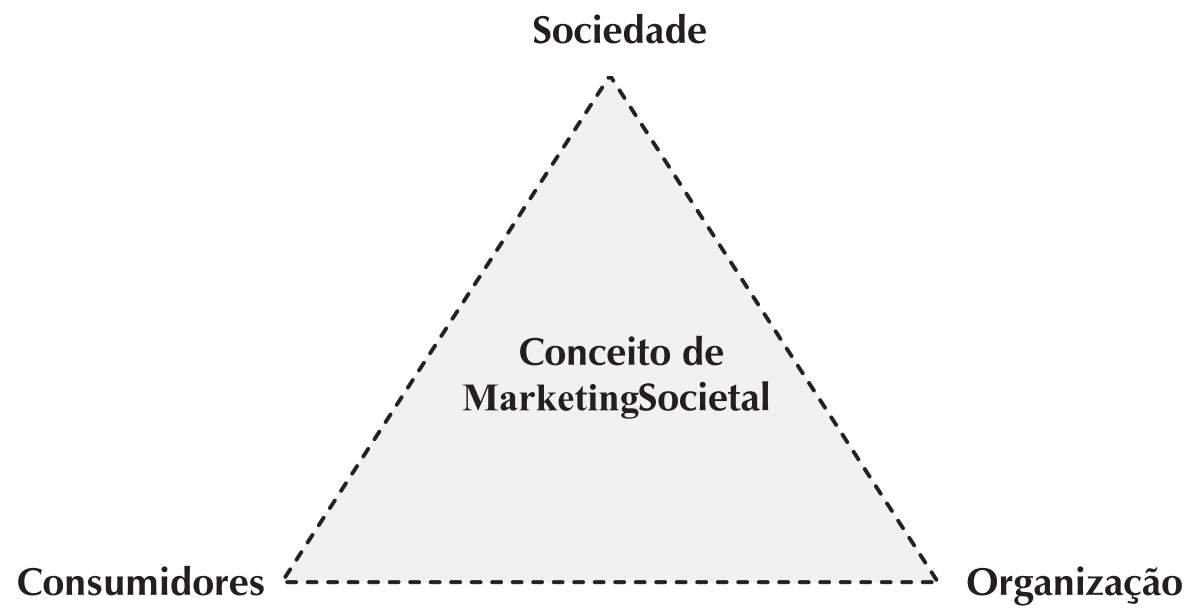

Figura 1 - As três considerações do Marketing Societal

Fonte: Adaptado de Kotler e Armstrong (2007, p. 9).

Schewe e Smith (1982) afirmam que a sociedade pode regulamentar uma organização através de leis, ações governamentais e afetar suas atividades no mercado ao recusar-se a comprar os produtos da organização. Dessa forma, as organizações que não atendem aos desejos e necessidades da sociedade são eliminadas da economia. Nesse sentido, Kotler e Armstrong (2007) chamam atenção para o fato de que as ideias sobre o Marketing Societal ganharam força, inicialmente, no setor de bens de consumo, mas também tem avançado no setor de serviços. $\mathrm{O}$ conceito de Marketing Societal exige que se equilibrem três fatores ao se definir uma política de mercado: os lucros da organização, os desejos do consumidor e os interesses da sociedade, como pode ser observado na figura 1.

Na perspectiva das três dimensões do Marketing Societal apresentada acima, Kotler e Armstrong (2007, p. 9) salientam que o Marketing Societal sustenta que a "organização deve determinar as necessidades, desejos e interesses dos mercados-alvo" e, então, "proporcionar aos clientes um valor superior, de forma a manter ou melhorar o bem-estar do cliente e da sociedade".

Giacomini (1993) reforça o fato de que a força Societal, que tem condicionado a aplicação do Marketing, mostra-se cada vez mais poderosa. A mentalidade "progresso, custe o que custar" não tem o alcance que tinha há alguns anos. O interesse individual na relação de consumo continua e continuará sendo forte, motivando o consumidor a adquirir sempre um produto em função de suas possibilidades, desejos e necessidades. Ocorre que os valores societais estão fazendo parte desses desejos e necessidades, já que cada um se dá conta de que muitos dos seus interesses individuais remontam valores coletivos e isto, seguramente, revela-se nas relações de consumo. Primeiro, porque a aquisição de um produto exterioriza um comportamento que será "medido" pela sociedade; o produto e a marca devem passar imunes por qualquer 
questionamento social. Segundo, pela própria consciência social que serve de referência para que as pessoas possam criticar os que desrespeitam esses valores.

Sob a ótica do conceito Societal de Marketing, o produto passa a ser visto como um conjunto de utilidades positivas e negativas, que devem ser aceitas pela sociedade como um todo, visando satisfazer as expectativas de benefício de um determinado segmento de mercado. Isto significa que diferente do Marketing comercial, sob o conceito Societal não vale tudo para agradar o consumidor.

Silva e Minciotti (2004) ressaltam que o Marketing Societal retrata que: antes de lançar um produto, antes de estabelecer preços, antes de distribuir o produto, antes de elaborar a estratégia promocional, a organização deve realizar testes, pesquisas, consultar a opinião pública e certificar-se de que a comercialização do produto não vai trazer nenhum prejuízo de ordem social. A prática do Marketing Societal envolve uma postura empresarial em consonância com a ética e valores sociais, porém requer planejamento consequente, práticas comerciais éticas, produtos ou serviços de qualidade, capacitação e motivação dos funcionários. Isto porque o consumidor, ao dispor do produto, está cuidando de sua saúde, segurança e outros, fato este que se estende a milhões de usuários.

Segundo os autores, pode-se afirmar que Marketing Societal refere-se à incorporação de considerações relativas aos problemas sociais em estratégias de Marketing desenvolvidas e implementadas com vistas a aumentar a aceitabilidade de produtos. Entretanto, o Marketing Societal possui um estreito relacionamento com o desenvolvimento sustentável, já que pode ser considerado como a utilização de técnicas e premissas de Marketing a ações de cunho econômico, social e ambiental, promovidas por organizações que não possuem causas sociais por finalidade. Assim sendo, pode-se reconhecer que o Marketing Societal - incorporação do desenvolvimento sustentável, ou sustentabilidade, nas estratégias de marketing - é decorrente da sua evolução, com vistas a oferecer valor aos públicos-alvo, de forma que sejam estimulados, podendo, então, ser utilizado por qualquer organização.

O Marketing Societal vai da perspectiva de mercados consumidores - marketing tradicional - para um segmento de consumidores preocupados com sua qualidade de vida, na qual menos passa a representar mais, e as decisões de compras são cada vez mais influenciadas pelo impacto do seu consumo no meio ambiente e sua saúde. Há uma mudança de paradigmas, em que o consumidor altera sua escala de prioridades no momento da escolha de produtos: aspectos impactantes no meio ambiente mudam de interesse marginal para o prioritário. Os indivíduos agem de acordo com seus valores por meio de suas decisões de compra.

Para Ikeda, Campomar e Miura (2000), a teoria de Marketing Societal está por trás dos movimentos contrários à globalização e ao consumo de massa, forçando os profissionais de marketing a procurarem uma nova estrutura para restabelecer a confiança do consumidor. Este novo conceito de marketing reconhece que a satisfação dos consumidores individuais não atende aos anseios da sociedade como um todo. E expressões que englobam os temas inter-relacionados são: desenvolvimento sustentável, liderança social e práticas éticas.

Outra questão a ser evidenciada na abordagem conceitual do Marketing Societal refere-se à questão ética, visto que uma filosofia de comportamento socialmente responsável deve concentrar um pensamento ético. Ainda que se possa referir ao marketing como uma disciplina, "a ética", sua implementação pode revestir-se de argumentos e/ou procedimentos "éticos" ou "não éticos" (LEISINGER; SCHMITT, 2001).

Nesse sentido, as organizações estão criando códigos de ética e desenvolvendo programas sobre questões éticas. Diversas implicações podem ser sugeridas quando o assunto é a efetiva prática de um comportamento empresarial ético, mas o que se propõe aqui é trazer a 
tona o fato de que o Marketing Societal não se efetivará sem o comportamento ético e socialmente responsável das organizações, por meio de seus gestores, orientado para o longo prazo (PEATTIE, 1995).

Outro fator que também pode ser levado em conta para um estudo mais aprofundado é a mudança de hábito da sociedade, que faz surgir consumidores mais exigentes, mais atentos às práticas empresariais e com uma percepção mais aguçada sobre a responsabilidade social e a ética praticada pelas organizações. Isso pode ser visto como força coercitiva à mudança de comportamento das organizações, fazendo-as ver os clientes "com outros olhos" e tendo que os tratá-los de maneira diferente, com mais respeito e responsabilidade.

\section{MARKETING SOCIETAL \& SUSTENTABILIDADE: RUMO AO CONSUMO SUSTENTÁVEL?}

Questões referentes à emissão de resíduos industriais e urbanos e exploração desordenada dos recursos naturais estão em voga atualmente e já não se pode mais ignorar a degradação ambiental causada por anos de ocupação irresponsável. Devido a esses fatores, é cada vez mais frequente a discussão a respeito do desenvolvimento da economia apoiado no conceito de sustentabilidade. Para Guimarães (1992), sustentabilidade significa a possibilidade de se obter continuamente condições iguais ou superiores de vida para um grupo de pessoas e seus sucessores em um dado ecossistema. Mediante isso, o conceito de sustentabilidade é manter as condições ambientais, obedecendo às leis da natureza, com uma perspectiva de longo prazo, para assegurar condições ambientais favoráveis para futuras gerações.

De acordo com Schenini et al. (2000), ao conectar-se o conceito de sustentabilidade com o desenvolvimento abordado pela economia, tem-se uma teoria complexa e, em parte, contraditória, porque uma sociedade, para se desenvolver e melhorar sua qualidade de vida, muitas vezes expande-se terriorialmente, sendo inevitável a degradação da natureza. Além disso, há o estímulo ao consumo para que o capital circule, gerando resíduo das embalagens e dos produtos descartados após o uso. O capital circulante normalmente cria um maior número de postos de trabalho, distribuindo renda, fornecendo poder aquisitivo aos cidadãos que se encontram à margem da sociedade, para mais consumo. Contraditoriamente, esta melhoria social acaba provocando um choque ideológico, pois o consumo acelerado aumenta o volume de resíduos, agravando o problema do lixo.

Em relação a este paradoxo, Almeida (2002) ressalta que novas regras econômicas são uma necessidade, na perspectiva do desenvolvimento sustentável, como um objetivo econômico mais consensual. Em lugar de pedir sempre mais consumo, o que deve ser priorizado é o consumo que pode ser levado adiante sustentavelmente. Cabe aqui enfatizar, que o conceito de desenvolvimento sustentável idealiza uma relação de harmonia entre os aspectos econômicos, sociais e ecológicos, factíveis e com grande possibilidade de uma empresa beneficiar-se ao realizar atividades no sentido de explorar os recursos naturais de maneira responsável e renovável.

Devido ao crescimento do ambientalismo e o aumento no volume de informações acerca das questões ambientais, a população, a passos lentos, mas constantes, está adquirindo uma maior consciência ecológica e tem crescido a fatia da sociedade mundial preocupada com a situação ecológica do planeta. Esta maior conscientização faz com que aumente a demanda por produtos ecológicos. Criou-se, assim, um novo e promissor mercado, que busca produtos e/ou serviços com isenção de danos ao meio ambiente, em que os chamados "consumidores ver- 
des" têm se mostrado dispostos a pagar um preço mais elevado para assegurar a preservação do meio ambiente (VEIGA, 2005).

Nesta situação, Baker (1995) salienta que a empresa deve adotar um modelo de gestão ambiental e atuar proativamente, pois, além do potencial de marketing, deve-se preocupar com a legislação ambiental existente, tornou-se financeiramente prejudicial à marca e à imagem da empresa, poluir e devastar o meio ambiente, sob a pena de multas, além de uma publicidade extremamente negativa. Em outras palavras, mesmo que o empresário não tenha consciência ecológica, que não perceba que está prejudicando o meio onde vive e esgotando os recursos naturais que seriam utilizados em sua empresa, mesmo assim, ele deverá repensar sua maneira de agir, pois o pagamento de multas e seus efeitos de marketing podem ter proporções tão grandes a ponto de representar sua falência.

Tais questões fazem com que a qualidade ambiental - tendo como desdobramento a qualidade de vida do consumidor - torne-se parte da qualidade total almejada pela empresa e desempenha um papel importante na estruturação da sua imagem. A "nova" marca, a marca ambiental, deve ser administrada com vistas ao impacto ambiental, lucros, responsabilidade pela comunicação da compatibilidade ambiental de sua marca, assumindo a perspectiva de longo prazo. A definição de uma política ambiental própria é a forma de a empresa explicitar seus princípios de respeito ao meio ambiente e sua contribuição para a solução racional dos problemas ambientais, cabendo à empresa trabalhar a imagem desses aspectos para melhorar e fortalecer sua imagem no mercado, ou seja, entre os consumidores (VALLE, 1995).

O consumidor, na ótica do Marketing Societal, é definido como aquele indivíduo que busca, para consumo, apenas produtos que causem menor ou nenhum prejuízo ao meio ambiente. Ou seja, aqueles que buscam conscientimente produzir, através do seu comportamento de consumo, um efeito nulo ou favorável sobre o meio ambiente e à sociedade como um todo. Apesar de todo clamor favorável à causa ecológica, é fato que o impacto disso na comunidade acadêmica não foi grande. Poucos estudos foram realizados com o objetivo de avaliar de maneira rigorosa o efeito do uso de argumentos de caráter ecológico com fins persuasivos (STRAUGHAN; ROBERTS, 1999). Holliday, Schmidheiny e Watts (2002) investigaram se consumidores expostos a anúncios contendo apelos ambientais com informações enganosas demonstram atitudes diferentes daqueles expostos com apelos ambientais não enganosos. O estudo concluiu, na época, que em ambos os grupos os consumidores se mostram a princípio céticos em relação a apelos ambientais em anúncios. Consequentemente, os profissionais de marketing precisam ser cuidadosos ao desenvolver campanhas, mediante CIM, com apelos ambientais.

Outro ponto a se levantar é o comportamento de compra do consumidor. Para Ottman (1994), os indivíduos estão agindo de acordo com seus valores por meio do poder de suas decisões de compra. Numa tentativa individual de se protegerem e de protegerem o planeta, esses consumidores estão moldando uma nova tendência, denominada consumerismo ambiental, só comprando produtos que considerem "verdes" e deixando produtos não-verdes na prateleira. Isto vai ao encontro de uma questão recorrente nos estudos que tentam identificar o perfil desses consumidores, que é a ausência de relação direta entre consciência ecológica e o comportamento de compra. Para Lages e Vargas Neto (2002), o conhecimento das questões ambientais, apesar de considerado como um indicador da possibilidade de ação consciente do consumidor, não parece significar, obrigatoriamente, um comportamento de compra ecologicamente correto.

O conceito de produtos "verdes" também é proveniente do Marketing Societal. São aqueles produtos ambientalmente corretos que reduzem a agressão ao meio ambiente e a saúde humana. Esses produtos "verdes" podem ser produtos que, através de uma reavaliação 
de processos de produção envolvidos, ou mesmo de reformulação ou diferenciação de produção, sofreram modificações com intuito de se tornarem ecologicamente corretos e agredirem minimamente possível o meio ambiente. A consideração de aspectos ambientais por parte das empresas também pode provocar o reposicionamento de alguns produtos. Em resposta à exposição aos raios ultravioletas e o risco de câncer de pele, tanto as loções com filtros solares quanto os óculos de sol passaram a enfatizar maior proteção solar do que a estética - um foco no Marketing Societal (OTTMAN, 1994; PEATTIE; CHARTER, 2003).

Mesmo tendo em vista toda essa preocupação com a ecologia nos dias atuais e o fato de existirem poucos estudos que testem os impactos dessa chamada "orientação verde" sobre os hábitos do consumidor brasileiro, não se pode afirmar que este chamado consumidor verde exista de forma significativa na sociedade brasileira. O Instituto AKATU pelo Consumo Consciente realizou duas pesquisas intituladas: "Os jovens e o consumo sustentável" e "O consumidor brasileiro e a construção do futuro", que visavam identificar as percepções dos jovens e da população adulta em geral sobre o impacto do ato de consumir. As pesquisas concluíram qu, os jovens, apesar de reconhecerem o impacto social do uso e descarte de produtos, não pensam sobre o processo de produção e consumo ao escolher os bens que consomem. Junto ao público adulto, as conclusões da pesquisa foram similares ao do público jovem e apontam que a reflexão, por parte do consumidor, sobre apelos ambientais em relação ao ato de comprar e consumir ainda são insignificantes para a população em geral (INSTITUTO AKATU, 2009).

Apesar da constante defesa por parte da literatura popular de administração propalando a existência desse "consumidor verde" e a grande influência que estes exercem sobre as estratégias empresarias - mais especificamente de Marketing Societal -, o que se verifica, na realidade, é uma falta de estudos que possam identificar a existência, no Brasil, desse consumidor ambientalmente responsável ou se o uso de apelos ecológicos pela mídia tem algum impacto no comportamento de compra do consumidor comum. Assim sendo, não se pode afirmar que o consumidor - ao menos no Brasil - possa ser enquadrado em uma postura de "consumidor verde" e que o seu comportamento esteja moldado em considerações ecológicas (INSTITUTO AKATU, 2009).

Assim, o avanço do Marketing Societal pode ser desencadeado pela nova dimensão que o meio ambiente - mediante sustentabilidade - passou a ocupar como fator de condicionamento de "troca" nos negócios entre o fabricante e o comprador. As empresas comprometidas com as questões societais tentam não apenas desenvolver uma limpeza ambiental, mas também evitar a poluição; desta forma o Peattie e Charter (2003) defendem que o trabalho "verde" exige que se pratique uma administração de três Rs: reduzir, reutilizar e reciclar. Na mesma perspectiva, Ottman (1994) acredita que o surgimento do Marketing Societal é resultado da constatação de que as empresas passaram a ser avaliadas não apenas com base no desempenho de seus produtos e/ou serviços, mas também com base na sua responsabilidade e papel que têm na sociedade contemporânea. A incorporação de valores ligados a preservação ambiental, de forma ética, pode favorecer uma oportunidade para a empresa fazer a "coisa certa", pode aumentar a imagem corporativa e da marca, economizar dinheito e abrir novos mercados para produtos que tenham o intuito de cumprir e satisfazer aos três pilares do Marketing Societal sociedade, consumidores e organização - e da sustentabilidade - econômico, social e ambiental - , como ilustra a figura 2. 


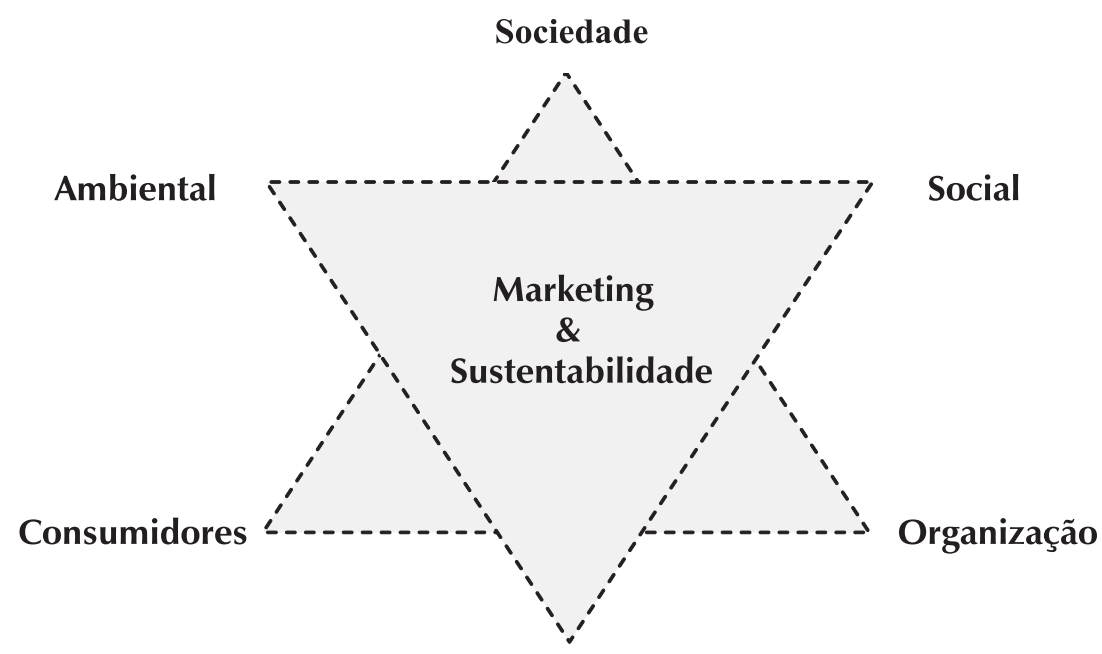

Econômico

Figura 2 - Os pilares do Marketing Societal e sustentabilidade Fonte: Desenvolvido pelos autores.

\section{MIX DE MARKETING: (RE)ARRANJO DAS VARIÁVEIS CON- TROLÁVEIS NA ÓTICA DO MARKETING SOCIETAL}

\subsection{Produto sustentável}

Produto significa a combinação de bens e serviços que a empresa oferece para um mercado-alvo. Para Charter et al. (2009), na era da sustentabilidade, a combinação ou o produto por si só deve ser: (a) eficiente, não poluidor, fácil de ser concertado; (b) reciclável; (c) embalado de forma ambientalmente correta; (d) manufaturado com recursos renováveis e com materiais locais, para evitar os custos com transportes; (e) não testável em animais; e (f) produzido sem uso da mão de obra infantil e sem uso de trabalho forçado. Assim, as empresas que se direcionam paa a sustentabilidade devem adotar essa orientação no processo de desenvolviemnto de bens e serviços, além da inovação.

Está se tornando cada vez mais difícil para as empresas criar e manter uma vantagem competitiva. Ainda assim, Kotler e Keller (2006) reforçam que o mercado é constantemente surpreendido pelo aparecimento de novos bens e serviços cujo índice de fracasso é contínuo. Segundo os autores, aproximadamente $80 \%$ de novos bens de consumo não dão certo e por isso as empresas estão percebendo que a marca é uma esperança de ganhar atenção e respeito em um mercado cada vez mais competitivo. Na perspectiva de Charter et al. (2009), esse também é um dos motivos pelos quais as empresas precisam praticar a sustentabilidade, pois ela está diretamente ligada à reputação e confiança da marca. Uma branding consolidada é algo que as organizações devem buscar desenvolver e manter.

Quanto ao desempenho do bem ou serviço, a marca representa um contrato com o cliente. Este contrato deve ser honesto, e é um engano achar que a propaganda constrói marcas. A propaganda sozinha chama a atenção para as marcas, mas estas são construídas de manei- 
ra holística, por meio de um conjunto de ferramentas, inclusive relações públicas (KOTLER; ARMSTRONG, 2007). A marca transparece processos, políticas e filosofias corporativas, ou seja, o que está por trás do produto, e, se os consumidores e demais partes interessadas - stakeholders - começarem, de fato, a preferir empresas que sejam mais responsáveis econômica, social e ambientalmente, então as marcas que refletem esses valores serão a preferenciais, na ótica dos mesmos (LAYRARGUES, 2000).

Além da marca, o "P" de produto envolve ainda características do bem, os serviços, o design e a embalagem. No contexto do desenvolvimento sustentável, esses itens ganham funções e importância no sentido de que, cada vez mais, as empresas terão que incluir em seus processos a avaliação sobre os impactos sociais, ambientais e econômicos para atender às expectativas da opinião pública e, assim, preservar sua imagem e presença no mercado (BAKER, 1995). O design, por exemplo, fornece um conjunto e conceito para o deenvolvimento bemsucedido de bens e serviços.

Entretanto, na era da sustentabilidade, o design leva em conta os impactos ambientais; passa a ser "ecodesign". De acordo com Holliday, Schmidheiny e Watts (2002), a ideia é incluir fatores ambientais desde o início do projeto do produto. Algumas estratégias abrangem o desenvolvimento de conceitos totalmente novos, com a seleção de matérias-primas de baixo impacto, a redução do uso de materiais, a otimização das técnicas de produção e dos sistemas de distribuição, a atenuação da influência negativa do uso sobre o meio ambiente e a otimização da vida útil do produto, assim como o do sistema fim de vida. Almeida (2002) prega que as empresas passem a enfatizar a redução do conteúdo de materiais utilizados em produtos e/ou serviços. A pesquisa e o desenvolvimento investidos na mudança de processos de aprimoramento na produção podem resultar em produtos de maior valor agregado e menor impacto ambiental. Detalhes de design podem ser eficazes na economia de energia e matéria-prima, tanto na fabricação quanto na utilização, reutilização e reciclagem. Enfim, o bom design exige que se pense em todas as atividades do cliente, abrangendo aquisição, uso e descarte.

Sobre as embalagens, o aumento do seu uso é um dos sinais mais notáveis da sociedade consumidora. As embalagens contêm informações úteis, protegem os produtos contra danos e deteriorizaçaõ e ajudam a resguardar os varejistas contra furtos nas lojas. No entanto, para Holliday, Schmidheiny e Watts (2002), a maioria delas foi projetada sem levar em conta impactos ambientais. Para Charter et al. (2009), apesar de ser a proteção do produto e de ser eficiente sob o ponto de vista do custo - pois pode reduzir os custos de fabricação e produção -, a embalagem está na linha de frente do debate sobre Marketing Societal e Sustentabilidade. É percebida como lixo, considerada descartável no final do consumo. OsPL plásticos duram para sempre no ambiente, e o papelão e o papel são fortemente associados com destruição de florestas. Porém, uma empresa que quer ser sustentável inclui entre seus objetivos o cuidado constante com o meio ambiente. Seus processos produtivos levam em conta os custos futuros, e não apenas os custos presentes, o que estimula a busca incessante de ganhos de eficiência e o investimento em inovação tecnológica e de gestão. O ganho de eficiência operacional é importante para se projetar o preço do produto, o segundo " $\mathrm{P}$ " do Mix de Marketing.

\subsection{Preço sustentável}

Preço é a quantia de dinheiro que os clientes têm de pagar para obter um bem ou serviço. A abordagem comum à fixação de preços consiste em apurar o custo e acrescentar a margem de lucro, lembrando-se sempre de que o custo do produtor não tem relação com a 
perspectiva do cliente quanto ao valor (KOTLER; ARMSTRONG, 2007). As empresas, por exemplo, que conseguem criar e comunicar mais valor por meio de características, estilo, valores agregados e outros diferenciados são capazes de impor um preço maior ao produto, hoje um dos maiores desafios do marketing em face à globalização, da hipercompetição e da Internet.

Antes do estabelecimento dessas macrotendências, as marcas superiores podiam cobrar qualquer coisa entre 20 e $50 \%$ a mais do que a marca média. Atualmente, uma marca superior, mesmo aquele que sugere algo sobre o sistema de valores da empresa como: ser inovadora; sensível ao cliente; ou ecologicamente responsável tem a sorte de conseguir cobrar $20 \%$ a mais (KOTLER; KELLER, 2006). O caminho então passa a ser o da eficiência de produção e o de conferir atributos de sustentabilidade à marca, produzindo mais com menos recursos, menos energia e utilizando materiais recicláveis. Ou seja, sendo ecoeficiente (PEATTIE; CHARTER, 2003).

Algumas empresas acreditam que ser ecoeficiente aumenta custos e, consequentemente, eleva os preços finais para o consumidor que, no Brasil, por exemplo, não está disposto a pagar por eles. Mas, segundo Charter et al. (2009), os consumidores estarão preparados para superar seus preconceitos no sentido de que os produtos "verdes" são mais caros, no momento em que suas características ambientais gerarem outros benefícios e no momento em que o valor intrínseco de se pagar mais por um produto esteja também latente em todos os outros sinais da empresa, como na forma como ela dispõe os produtos na prateleira e como ela utiliza este canal para educar nas questões de sustentabilidade. O grande desafio é traduzir o incremento ambiental, social e econômico em valor para o consumidor, ao menos, por algo que ele esteja disposto a pagar.

\subsection{Distribuição sustentável}

A distribuição (ou praça) envolve as atividades da empresa que tornam o produto disponível aos consumidores-alvo, os canais, o estoque, o transporte e a logística (RICHERS, 2000). Todas as empresas devem pesquisar meticulosamente as diferentes alternativas de canais para distribuir seus bens e/ou serviços. Quanto maior o número de canais, maior será o alcance da empresa no mercado.

Holliday, Schmidheiny e Watts (2002) lembram que esta distribuição física - atacado e varejo - também tem impactos ambientais diretos e indiretos. Para os autores, é precio fazê-la com cautela e prudência, pois não envolve somente onde os consumidores compram, mas também a movimentação dos bens da empresa.

O número de canais para comprar qualquer bem ou serviço está se multiplicando, e os distribuidores e varejistas estão ficando mais poderosos, podendo controlar o caminho para o cliente (RICHERS, 2000). Diante disso, Holliday, Schmidheiny e Watts (2002) ressaltam que, no contexto do desenvolvimento sustentável, por exemplo, os clientes podem contribuir muito para atuarem como educadores no processo de consumo, pois captam rapidamente as tendências subjacentes a milhares de decisões isoladas de cada consumidor. Maignan e Ferrel (2004) apontam que os atacadistas e também os varejistas podem insistir para que os fabricantes forneçam informações contínuas sobre seus processos de produção, quanto ao consumo de energia, uso de materiais e poluição. Alguns varejistas já dão preferência aos que têm comprometimento com o desenvolvimento sustentável. O importante é que eles tenham visão de gestão ambiental, social e econômica, cobrando postura de agricultores, fornecedores e manufatureiros. Eles devem encorajar uma infraestrutura de reciclagem, disponibilizando containers de retorno 
e podem atuar com logística reversa, coletando bens para o reprocessamento ou recolhendo materiais que não podem ser remanufaturados. Além disso, podem fornecer informações através do " $\mathrm{P}$ " de promoção, ajudando os clientes e demais partes interessadas a fazerem melhores escolhas.

\subsection{Promoção sustentável}

O principal desafio, hoje em dia, é chamar a atenção de alguém. Os consumidores sofrem a pressão do tempo, e o difícil é descobrir novas maneiras de chamar sua atenção e fixar uma amrca em suas mentes. $\mathrm{O}$ " $\mathrm{P}$ " de promoção envolve as atividades relacionadas ao mix de comunicação: propaganda, publicidade, relações públicas, vendas pessoais, promoção de vendas, merchandising etc., de modo a comunicar os pontos fortes da marca e do produto e/ou serviço, com o objetivo de convencer os clientes-alvo a comprá-lo (KOTLER; ARMSTRONG, 2007). No contexto da sustentabilidade, é possível utilizar essas atividades para reforçar que as responsabilidades ambientais, sociais e econômicas da empresa são realmente importantes para a organização e que a imagem que está sendo transmitida de fato traduz a realidade.

Para Charter et al. (2009), é importante que a força de vendas, por exemplo, seja educada nas questões do desenvolvimento sustentável e com a capacidade de comunicar os benefícios dos bens e serviços sustentáveis da organização a qualquer consumidor ou cliente da empresa. É preciso que a política de vendas promova um comportamento ético, que a equipe entenda a política de sustentabilidade da empresa, que recebam treinamentos e incentivos para promover ainda mais a política de desenvolvimento de produtos sustentáveis.

Apesar de ser uma variável importante no mix de Marketing, sua principal limitação é o fato de ser um monólogo - na maioria das ocasiões. E, atualmente, no contexto da sustentabilidade, é essencial desenvolver sistemas de comunicação que permitam a troca de informações com clientes e demais partes interessadas. Nesse sentido, o diálogo acerca dos destinos dos negócios torna-se fundamental. Isto porque, como afirmam Holliday, Schmidheiny e Watts (2002), o diálogo diminui as incertezas, os mal-entendidos, o risco e a responsabilidade por danos, aumenta a aceitação das atividades da empresa pelo público e torna os reguladores mais previsíveis.

Em um mundo globalizado, a transparência e o gerenciamento da reputação tornam-se elementos centrais da gestão corporativa. Não se podem manter diálogos duradouros com as partes interessadas e, ao mesmo tempo, preservar com êxito certos segredos (PEATTIE; CHARTER, 2003). A transparência torna difícil a negligência ambiental. Almeida (2002) reforça que gerenciar a reputação é tarefa mais ampla do que apenas utilizar recursos de marketing para melhorar a imagem. Exige comprometimento de toda a empresa com os valores humanos, com a ética e a transparência. Há de se reconhecer que a transparência é tema crucial para as empresas movidas pela sustentabilidade (HOLLIDAY; SCHMIDHEINY; WATTS, 2002). Por tudo isso, o marketing, como principal responsável pela conexão da empresa com o ambiente, deve conhecer melhor de que forma contribuir com a orientação para o desenvolvimento sustentável. 


\section{POR QUE MARKETING SOCIAL NÃO É SINÔNIMO DE MARKETING SOCIETAL?}

O Marketing Social utiliza-se das premissas, dos conceitos, das estratégias e das técnicas de marketing em causas sociais sem caráter lucrativo. O Marketing Social tem como desafio e objetivo provocar - ou gerar - uma mudança social, ou seja, a perspectiva da troca para melhorar a qualidade de vida dos indivíduos ou evitar que, quando obtida, seja reduzida num horizonte de longo prazo. A produção de mudanças sociais é difícil com qualquer estratégia, especialmente, quando exige uma resposta voluntária (MAZZON, 1981).

A mudança social é um fenômeno coletivo que afeta as condições de vida de seus componentes, os quais atuam no sentido de originar, acentuar, diminuir ou impedir as modificações de partes ou da totalidade da organização social. Essas mudanças podem ocorrer espontaneamente, à medida que os próprios partícipes notem inconsistências em relação às mais diversas situações; ou de maneira planejada, buscando atingir objetivos pré-estabelecidos (TEIXEIRA; MAZZON, 2000). Assim sendo, pode-se definir uma campanha de mudança social como "um esforço organizado, feito por um grupo - o agente da mudança - a fim de convencer terceiros - os adotantes escolhidos como alvo - a aceitar, modificar ou abandonar certas ideias, atitudes, práticas e comportamentos" (KOTLER; ROBERTO, 1992, p. 6).

Com efeito, Kotler (1978) estabeleceu quatro categorias de mudança social, seguindo um determinado grau de dificuldade:

(a) Mudança cognitiva: uma grande quantidade de causas sociais tem o escopo de apenas informar a opinião pública, modificando seu nível de conhecimento sobre um determinado assunto. Alguns exemplos são: campanhas para informar novas alíquotas tributárias; campanha informativa sobre alterações nas condições de trânsito, informações acerca das ações do governo etc.;

(b) Mudança de ação: esta é uma causa social que objetiva alterar a atitude das pessoas, tentando, na maioria das vezes, fazer com que uma quantidade máxima de pessoas realize uma ação específica, durante um dado período. São alguns exemplos desse tipo de causa social as campanhas de doação de agasalhos, de vacinação em massa, de combate às doenças sexualmente transmissíveis;

(c) Mudanças de comportamento: algumas causas sociais têm o objetivo de ajudar as pessoas a alterar, total ou parcialmente, seu comportamento. Campanhas contra o vício do fumo e entorpecentes e campanhas para a adoção de hábitos saudáveis de vida, são exemplos dessa causa social;

(d) Mudanças de valor: aqui se enquadram as causas sociais que necessitam de mudanças nas crenças e valores das pessoas, como, por exemplo, as campanhas contra a segregação racial e contra o desarmamento.

Para Silva e Minciotti (2004), o Marketing Social pode contribuir, significativamente, para o aumento da adesão dos cidadãos a essas causas e para a melhoria da qualidade de vida atual e futura, entretanto, sem ter com finalidade o lucro, diferentemente do que ocorre com o Marketing Societal. Em virtude de "falácias" de tradução de livros e revistas, de compreensão de conceitos na área de Gestão - mais especificamente em Marketing - e de distorções cometidas pelas mídias, os conceitos, práticas e técnicas de Marketing Societal vêm sendo interpretados como sendo de Marketing Social.

Assim sendo, o objetivo deste tópico neste ensaio é o de esclarecer esses conceitos, pois já há obras disponíveis nas prateleiras das livrarias e na Internet, apresentando conceitos de Marketing Societal intitulado de Marketing Social. Tendo em vista que, constantemente, esses 
conceitos, práticas e técnicas vêm sendo confundidas, pretende-se, além de esclarecer as diferenças entre Marketing Societal e Marketing Social, esclarecer também duas outras "ferramentas" que se aproximam do Marketing Societal, mas que não o são. Elas são denominadas de Propaganda Institucional e Responsabilidade Social. Cabe aqui um breve esclarecimento acerca das quatro "ferramentas":

(a) Marketing Social: é o resultado da expansão do Marketing Tradicional que abordou, além de produtos e/ou serviços, as pessoas e as ideias e causas. Portanto, é a aplicação dos conceitos e ferramentas de Marketing às ideias, às causas e aos produtos sociais, com vistas a influenciar a sua aceitabilidade, por exemplo, campanhas da vacina da gripe H1N1 (SILVA; MINCIOTTI, 2004);

(b) Marketing Societal: é a incorporação de considerações relativas aos problemas sociais decorrentes de certas práticas de Marketing que são desenvolvidas e implementadas com o objetivo de aceitabilidade de produtos. Desse modo, há um relacionamento estreito com a Responsabilidade Social e com as premissas de Marketing a ações de cunhos sociais promovidos por empresas que não têm as causas sociais como finalidade, por exemplo, latas de alumínios recicláveis (GIACOMINI, 1993);

(c) Propaganda Institucional: é a promoção da organização, em vez do produto. Propõe-se a melhorar as relações de uma empresa com vários grupos, considerando consumidores, membros dos canais, fornecedores, acionistas, funcionários e público em geral. Por exemplo, o governo brasileiro usa a Propaganda Institucional para promover o Brasil como um local para fazer turismo (ROCHA; CHRISTENSEN, 1999; MCCARTHY; PERREAULT, 1997);

(d) Responsabilidade Social: há dois modelos, por meio de ações sociais, como doações a instituições de caridade, ou por meio de processos que contribuam positivamente à sociedade, por exemplo, a adoção de creches ou asilos, incorporados ao plano de estratégias da empresa (LEISINGER; SCHMITT, 2001).

Constata-se que as três últimas mantêm um compromisso com o lucro, ou seja, mantêm um caráter lucrativo, embora favoreçam as causas sociais, porém, quase sempre se revertem uma melhoria da imagem e do posicionamento das empresas no mercado. O Marketing Social não tem caráter lucrativo, isso pode ser comprovado, já que sua aplicação é feita por Instituições Públicas e Organizações Não-Governamentais (ONGs) em prol de sanar "problemas" ou "carências" sociais da sociedade mediante políticas públicas.

Enfim, para finalizar - ao menos neste ensaio - a discussão entre Marketing Societal versus Marketing Social - que intitula o presente tópico -, apresenta-se o quadro 2, que resume as distinções, de modo a esclarecer os conceitos, as práticas, as técnicas e as finalidades.

Portanto, se uma organização resolver adotar uma creche, cuidar de uma praça, levar funcionários para doar sangue, destinar a arrecadação de um dia de venda de hambúrgueres para cuidar do câncer infantil ou qualquer outra benemérita deve ser aplaudida, porém, jamais rotulada de práticante de Marketing Social ou Societal. Na realidade, ela estará fazendo uma Propaganda Institucional, ou uma Responsabilidade Social, ou, ainda, cumprindo seu papel social, o que, aliás, já é bastante.

Por outro lado, se uma organização resolver desenvolver produtos "verdes" ou "ecológicos", como os automóveis elétricos movidos à energia renovável no setor automobilístico; ou como os biomóveis baseados no conceito de Green Home, do qual o processo produtivo cadeia de valor - procura reduzir o consumo de energia e utilizar embalagens recicláveis; ou, ainda, como a impermeabilização de ciclovias e calçadas mediante borracha triturada de pneus; bem como qualquer outra ação similar, também é louvável e merece ser aplaudida, entretanto, não se pode rotulá-la como uma estratégia de Marketing Social. Isto porque essas estratégias 


\begin{tabular}{|c|c|c|}
\hline & Marketing Societal & Marketing Social \\
\hline Utilização & Organizações lucrativas & Organizações não-lucrativas \\
\hline Fator desencadeador & Investimento social & Melhores condições sociais \\
\hline Foco principal & $\begin{array}{c}\text { Aceitabilidade de produtos e } \\
\text { bem-estar da sociedade }\end{array}$ & $\begin{array}{c}\text { Mudança social e } \\
\text { bem-estar da sociedade }\end{array}$ \\
\hline Orientação & O consumidor & O benefício do cidadão \\
\hline
\end{tabular}

Quadro 2 - Marketing Societal versus Marketing Social

Fonte: Adaptado de Silva e Minciotti (2004).

têm como intuito o bem-estar da sociedade mediante promoção da aceitabilidade de produtos e a imagem da organização, ou seja, referem-se às estratégias de Marketing Societal

\section{CONSIDERAÇÕES FINAIS}

A evolução do conceito de Marketing parece atender às preocupações da sociedade de forma semelhante com o que, no campo econômico, fazia evoluir o conceito de desenvolvimento. Na década de 1970, ao contrário da visão predominante das décadas de 1950 e 1960, quando o desenvolvimento era medido simplesmente a partir da sua dimensão de crescimento econômico, intensifica-se por razões morais e ambientais a discussão sobre a interdependência de conservação ambiental e desenvolvimento e emerge o termo desenvolvimento sustentável.

O entendimento de que há um inter-relacionamento entre desenvolvimento sustentável e Marketing Societal pressupõe a inserção dessa temática num contexto de sociedade sustentável, em que os conceitos de desenvolvimento sustentável e de Marketing Societal convergem para o longo prazo como meta temporal na avaliação das consequências das alternativas de satisfação das necessidades humanas (ou dos consumidores), com o propósito de garantir a sustentabilidade de seus próprios objetivos.

Esse entendimento deve também considerar que as diretrizes de desenvolvimento sustentável situam-se no âmbito macroeconômico; que o planejamento empresarial de Marketing sob a filosofia societal situa-se no âmbito microeconômico, no qual, por sua vez, estão os programas de ação empresarial, visando à aceitabilidade de produtos e o bem-estar da sociedade como limite da satisfação do consumidor no longo prazo.

Evidentemente, não se pode esperar da implementação da atividade de Marketing quer na sua dimensão Societal, quer Social - o atendimento a todos os valores presentes no 
conceito de desenvolvimento sustentável, especialmente os relacionados ao combate da miséria e equidade distributiva, entre outros. No entanto, pode-se entender a sua aplicação como um esforço maior no sentido de estimular a incorporação às atividades empresariais e ao mercado consumidor, os aspectos sociais e éticos, ainda relegados na atividade de troca.

Há, ainda, um amplo espaço a ser ocupado no mercado pela aplicação de Marketing Societal, visto que, sob esse conceito, o valor profissional de Marketing - enquanto agente de gestão da atividade de Marketing Empresarial - não é medido pela sua capacidade de vender o "ruim" pelo "bom", mas sim por sua capacidade de vender o "bom", mesmo que seja mais caro, eliminando, ao mesmo tempo, o "ruim", ainda que seja mais "barato" sob a ótica de curto prazo.

Nesse sentido, a atividade de Marketing estaria incorporada a um processo de purificação do mercado, a partir da colocação de produtos favoráveis ao meio ambiente, no seu sentido holístico, ou seja, produtos cuja concepção tenha, no início de seu ciclo, a busca sustentável da matéria-prima, a compatibilidade ambiental do processo produtivo; a segurança no seu armazenamento e transporte para distribuição a orientação sobre o seu consumo e descarte.

Por tudo isto, o Marketing Societal não pode ser visto por sua eficiência na mudança do comportamento do consumidor. Isso caberá aos programas de Marketing Social, implementados por organizações não-lucrativas. Entretanto, o Marketing Societal deve ser visto por sua capacidade de desencadear investimento social, ao ofertar produtos "verdes", ou seja, aqueles com características de Sustentabilidade e ao gerar programa de comunicação persuasiva para a efetivação da demanda. Comunicar ao consumidor aquilo que o sensibiliza nesse ambiente da Sustentabilidade, fazendo valer as estratégias de branding.

\section{REFERÊNCIAS BIBLIOGRÁFICAS}

ALMEIDA, F. O bom negócio da sustentabilidade. Rio de Janeiro: Nova Fronteira, 2002.

ANDRADE, A.; ROSSETTI, J. P. Governança corporativa: fundamentos, desenvolvimento etendências. São Paulo: Atlas, 2006.

BAKER, P. Gestão ambiental: a administração verde. Rio de Janeiro: Qualitymark, 1995.

CAMARGO, A. L. B. Desenvolvimento sustentável: dimensões e desafios. São Paulo: Papirus, 2003.

CHARTER, M.; PEATTIE, K.; OTTMAN, J.; POLONSKY, M. J. Marketing and sustainability. Disponível em: < http:www.cfsd.org.uk/smart-knownet $>$. Acesso em: 30 set. 2009.

CORRADO, F. K. M. A força da comunicação. São Paulo: Makron, 1994.

DONAIRE, D. Gestão ambiental na empresa. São Paulo: Atlas, 1995.
GIACOMINI, G. Uma abordagem societal do marketing e publicidade. Revista de Comunicação e Sociedade da UMESP, n. 19, , p. 103-114, mar. 1993.

GUIMARÃES, R. P. Políticas de meio ambiente para o desenvolvimento sustentável: desafios institucionais e setoriais. Planejamento e Políticas Públicas, IPEA, n. 7, p. 57-80, jun. 1992.

HOLLIDAY, C.; SCHMIDHEINY, S.; WATTS, P. Cumprindo o prometido: casos de sucesso de desenvolvimento sustentável. Rio de Janeiro: Campus, 2002.

IKEDA, A. A.; CAMPOMAR, M. C.; MIURA, I. K. Combate ao desperdício de energia elétrica: um caso de marketing societal. Revista de Administração da Faculdade de Economia e Administração da USP, v. 35, n. 01, p. 05-13, jan./mar. 2000.

INSTITUTO AKATU. Pelo consumo consciente. Disponível em: < http://www.akatu.org.br>. Acesso em: 30 nov. 2009. 
KOTLER, P. Marketing para organizações sem fins lucrativos. São Paulo: Atlas, 1978.

KOTLER, P.; ARMSTRONG, G. Princípios de marketing. 12. ed. São Paulo: Pearson Prentice Hall, 2007.

KOTLER, P.; KELLER, K. L. Administração de marketing. 12. ed. São Paulo: Pearson Prentice Hall, 2006.

KOTLER, P.; ROBERTO, E. L. Marketing social: estratégias para alterar o comportamento do público. Rio de Janeiro: Campus, 1992.

LAGES, N.; VARGAS NETO, A. Mensurando a consciência ecológica do consumidor: um estudo realizado na cidade de Porto Alegre. In: ENANPAD, 26., 23-26 ago. 2002, Salvador. Anais... Salvador: 2002.

LAYRARGUES, P. P. Sistemas de gerenciamento ambiental, tecnologia limpa e consumidor verde: a delicada relação empresa-meio ambiente no ecocapitalismo. Revista de Administração de Empresas, São Paulo, v.40, n. 2, p.80-88, abr./jun. 2000.

LEISINGER, K. M.; SCHMITT, K. Ética empresarial: responsabilidade global e gerenciamento moderno. Rio de Janeiro: Vozes, 2001.

MAIGNAN, I.; FERRELL, O. C. Corporate social responsibility and marketing: an integrative framework. Journal of The Academy Of Marketing Science, v. 3, n. 1, , p. 3-19, jan. 2004.

MAZZON, J. A. Análise do programa de alimentação do trabalhador sob o conceito de marketing social. Tese (Doutorado em Administração)-Faculdade de Economia e Administração-Universidade de São Paulo, São Paulo, 1981.

MCCARTHY, E. L.; PERREAULT, W. D. Marketing essencial: uma abordagem gerencial e global. São Paulo: Atlas, 1997.

MOTTA, S. L. S.; ROSSI, G. B. A Influência do fator ecológico na decisão de compra de bens de conveniência: um estudo exploratório na cidade de São Paulo. Revista de Administração USP, São Paulo, v. 38, n. 1, p. 46-57, jan./mar. 2003.
OTTMAN, J. A. Marketing verde: desafios e oportunidades para nova era do marketing. São Paulo: Makron, 1994.

PEATTIE, K. Environmental marketing management: meeting the green challenge. London: Pitman, 1995.

PEATTIE, K.; CHARTER, M. Green marketing. In: BAKER, Michael (Ed.). The marketing book. Gram Britannia: Butter Wealth, 2003.

RICHERS, R. Marketing: uma visão brasileira. 7. ed. São Paulo: Negócio, 2000.

ROCHA, A.; CHRISTENSEN, C. Marketing: Teoria e Prática no Brasil. 2 ed. SP: Atlas, 1999.

SCHENINI, P. C.; SCHMITT, V.; SILVA, F. A.; PEREIRA, M. F. Marketing verde como uma abordagem estratégia frente ao novo perfil de consumo. In: CONGRESSO DA SOBER (SOCIEDADE BRASILEIRA DE ECONOMIA E SOCIOLOGIA RURAL) "QUESTÕES AGRÁRIAS, EDUCAÇÃO NO CAMPO E DESENVOLVIMENTO", 64., 23-27 Jul. 2006, Fortaleza. Anais... Cd-Room.

SCHEWE, C. D.; SMITH, R. M. Marketing: conceitos, casos e aplicações. Rio de Janeiro: McGraw-Hill, 1982.

SILVA, E. C.; MINCIOTTI, S. A. Marketing ortodoxo, societal e social: as diferentes relações de troca com a sociedade. Revista Brasileira de Gestão de Negócios, São Paulo, ano 7, p. 15-22, abr. 2005.

SMITH, S. B. M.; RIBAS, J. R. O espectro verde na sustentabilidade ambiental. In: SIMPEP, 13., Bauru, 6-8 nov. 2006. Anais...Cd-Room.

STRAUGHAN, R. D.; ROBERTS, J. Environmental segmentation alternatives: a look at green consumer behavior in the new millennium. Journal of Consumer Marketing, v. 16, n. 6, p. 558-575, 1999.

TEIXEIRA, M. L. M.; MAZZON, J. A. Orientação ética quanto à mudança social envolvendo stakeholders. Revista de Administração Mackenzie, São Paulo, ano 01, n. 01, p. 51-65, 2000.

VALLE, C. E. Qualidade ambiental: como ser competitivo protegendo o meio Ambiente. São Paulo: Pioneira, 1995.

VEIGA, J. E. Desenvolvimento sustentável: o desafio do século XXI. Rio de Janeiro: Garamond, 2005. 